UDC 332.1

LBC 65.050

\title{
DESCRIPTIVE ANALYSIS OF ENTREPRENEURIAL RISKS AND THE WAYS OF THEIR REGULATION
}

\author{
Marina E. Buyanova \\ Volgograd State University, Volgograd, Russian Federation
}

Nataliya A. Mikhaylova

Moscow State University of Humanities and Economics, Moscow, Russian Federation

\begin{abstract}
The development of entrepreneurship is accompanied by emergence of new risks in different spheres of economic activity. The important task thus consists in finding ways and optimal conditions of entrepreneurial risks regulation. The entrepreneurial risk is determined by the influence of external (objective) and internal (subjective) factors. Regulation of risks includes several stages, the qualitative analysis of all possible risk factors being the first of them. The authors analyze entrepreneurial risks grouped by the indices of economic activity carried out by entrepreneurs in the regions, as well as their problems and limitations. The main ways of risks reduction and the directions of their regulation in the Volgograd region are suggested. It is noted that the Volgograd region suffers from commercial, economic, managerial risks (budget implementation, high State debt and its prospective growth) and industrial risks due to a high wear and tear of the fixed capital. The enterprises of fuel and power complex are in better conditions: they are in the list of top ten tax payers and investors. Large investment projects have also been launched in the chemical industry. The wholesale and retail enterprises, as well as construction companies carry the highest risk exposure. The significant risks are traditionally typical of agricultural enterprises but they benefit from State support together with the enterprises of chemical industry. The diversification of regional economy is a priority direction of entrepreneurial risks regulation against the background of poor social and economic conditions for entrepreneurship development.

Key words: regional economy, entrepreneurship, risk management, risk regulation, economic diversification.

Citation. Buyanova M.E., Mikhaylova N.A. Descriptive Analysis of Entrepreneurial Risks and the Ways of Their Regulation. Vestnik Volgogradskogo gosudarstvennogo universiteta. Seriya 3, Ekonomika. Ekologiya [Science Journal of Volgograd State University. Global Economic System], 2018, vol. 20, no. 3, pp. 25-33. (in Russian). DOI: https://doi.org/10.15688/jvolsu3.2018.3.3
\end{abstract}

УДК 332.1

ББК 65.050

\section{ДЕСКРИПТИВНЫЙ АНАЛИЗ ПРЕДПРИНИМАТЕЛЬСКИХ РИСКОВ И ВЫЯВЛЕНИЕ НАПРАВЛЕНИЙ ИХ РЕГУЛИРОВАНИЯ}

\author{
Марина Эдуардовна Буянова \\ Волгоградский государственный университет, г. Волгоград, Российская Федерация
}

\section{Наталия Александровна Михайлова}

Московский государственный гуманитарно-экономический университет, г. Москва, Российская Федерация

Аннотация. Развитие предпринимательства сопровождается появлением новых рисков, относящихся к той или иной сфере деятельности. Важным представляется выявление направлений регулирования риска предпринимательской деятельности, а также условий ее осуществления. Предпринимательский риск определяется влиянием внешних (объективных) факторов и внутренних (субъективных). Регулирование рисков вклю- 
чает несколько этапов, и первым из них является качественный анализ всех возможных факторов риска. В статье проанализированы предпринимательские риски, выделенные по показателям ведения хозяйственной деятельности субъектов предпринимательства в регионе, обозначены их проблемы и ограничения, а также выделены основные способы снижения рисков и направления их регулирования в Волгоградской области. В исследовании отмечено, что в Волгоградской области существенны коммерческие, экономические, управленческие риски (неисполнение бюджета, высокий госдолг и в перспективе его наращивание), высоки промышленные риски в силу значительного износа основных фондов. В регионе традиционно в лучшем положении предприятия ТЭК, они - в десятке первых налогоплательщиков и инвесторов; крупные инвестпроекты начаты в химической промышленности. Наибольшие риски у предприятий оптовой и розничной торговли, строительства. Большие риски традиционно сопровождают сельскохозпроизводителей, но они вместе с предприятиями химической отрасли пользуются господдержкой. Среди основных направлений регулирования предпринимательских рисков, выделенных с точки зрения видов рисков, приоритетным направлением для Волгоградской области в силу не лучших социально-экономических условий развития предпринимательской деятельности считается диверсификации экономики региона.

Ключевы слова: региональная экономика, предпринимательство, риск-менеджмент, регулирование рисков, диверсификация экономики.

Цитирование. Буянова М. Э., Михайлова Н. А. Дескриптивный анализ предпринимательских рисков и выявление направлений их регулирования // Вестник Волгоградского государственного университета. Серия 3, Экономика. Экология. - 2018. - Т. 20, № 3. - С. 25-33. - DOI: https://doi.org/10.15688/jvolsu3.2018.3.3

Отрицательная динамика числа субъектов малого и среднего бизнеса обусловлена высокими рисками ведения хозяйственной деятельности, с одной стороны, и отсутствием практики их предупреждения - с другой. Повсеместное внедрение систем управления рисками крайне затруднено даже на крупных предприятиях в силу недостатка средств, опыта и квалифицированных специалистов. Для малого бизнеса регулирование предпринимательских рисков невыполнимо по тем же причинам, однако в настоящее время ситуация на рынке меняется и многие финансовые организации, диверсифицируя свою деятельность, предлагают комплекс услуг по предотвращению, в том числе страхованию, предпринимательских рисков.

Структура экономики региона имеет индустриальный характер, и этой сфере присущи производственные, экологические и прочие риски, которые по своим экономическим последствиям охватывают регион в целом. Поэтому для диверсификации региональных рисков необходимо создание конечных потребительских товаров, местных брендов, развитие сферы услуг. Эта задача выполнима субъектами малого и среднего бизнеса, микропредприятиями, риски хозяйствования которых должны иметь адекватные способы их регулирования.

Теоретические и практические аспекты предпринимательских рисков и направ- лений их регулирования рассматривали в своих трудах ряд исследователей: И.Т. Балабанов, А.Н. Бордовских, В.М. Гранатуров, В.Л. Гуревич, Н.И. Денисова, М.Р. Дзагоева, В.С. Кабаков, Н.А. Казакова, М. Круи, М.М. Кутьина, М.Г. Лапуста, И.А. Подколзина, Г.А. Тактаров, В.Н. Уродовских, Е.А. Федорова, В.Е. Шкурко.

Наибольшее значение в анализе риска и неопределенности имели работы классиков: Р. Кантильона, Дж.М. Кейнса, Ф. Найта и др.

Цель исследования - дескриптивный анализ предпринимательских рисков и выявление направлений их регулирования в Волгоградской области. В соответствии с поставленной целью решены следующие задачи: проведена оценка рисков ведения хозяйственной деятельности субъектами предпринимательства в Волгоградской области; предложены основные направления регулирования предпринимательских рисков в регионе.

В статье проанализированы предпринимательские риски, выделенные по показателям ведения хозяйственной деятельности субъектов предпринимательства в регионе, обозначены их проблемы и ограничения, а также выделены основные способы снижения рисков и направления их регулирования в Волгоградской области.

Исследование базируется на изучении данных Федеральной службы государствен- 
ной статистики РФ и ее территориальных органов, Министерства экономического развития РФ; стратегических и программных документов РФ, органов власти субъектов РФ и органов местного самоуправления. Используются материалы монографических исследований, научные статьи, публикации отечественных и зарубежных ученых в периодических изданиях и в информационных ресурсах сети Интернет в области предпринимательских рисков и направлений их регулирования, а также анализа риска и неопределенности; собственные авторские расчеты.

В работе использовались методы компаративного и дескриптивного анализа, корреляционного анализа, а также общенаучные методы системного, структурно-функционального, статистического и сравнительного анализа, методы классификации и сравнения, метод экспертных оценок, табличные и графические приемы визуализации статистических данных.

Предпринимательский риск определяется влиянием внешних (объективных) факторов и внутренних (субъективных). Регулирование рисков включает несколько этапов, и первым из них является качественный анализ всех возможных факторов риска. Остановимся на тех, на которые предприниматель не может повлиять: это региональные предпринимательские риски.

По итогам исследования 2016 г., проведенного агентством «Эксперт РА», Волгоградская область имеет 52-й ранг инвестиционного риска. Ситуация улучшилась на две позиции по сравнению с 2015 г., тогда был 54-й ранг. Рассмотрим более подробно составляющие риска Волгоградской области (социальный, экономический, финансовый, криминальный, экологический, управленческий) и сравним с соседними субъектами ЮФО (Краснодарский край, Ростовская область и Астраханская область) (табл. 1).
По интегральному инвестиционному риску Волгоградская область значительно уступает Ростовской области и тем более Краснодарскому краю, имеющему минимальный инвестиционный риск. Наихудшая ситуация в нашем регионе с управленческим риском, в том числе с качеством управления региональным бюджетом (наряду с этим способность региональных властей привлекать объем инвестиций и обеспечивать население минимальным уровнем необходимых социальных услуг включены Эксперт РА в оценку управленческого риска).

Госдолг Волгоградской области превысил $90 \%$ от уровня ее доходов за 2016 г. и составил 53,4 млрд руб.; по сравнению с 2015 г. он увеличился на $11,7 \%$. В отличие от областей той же группы риска, темпы роста госдолга Волгограда выше. Катастрофичность ситуации заключается в том, что очередной кредит будет взят для покрытия старого долга. Это показатель низкого качества исполнения бюджета и бюджетного планирования основных составляющих управленческого риска. Существует большая вероятность риска невыполнения своих обязательств перед регионом и остановки программ. Для тех предпринимателей, которые только открыли свое дело, внешние факторы риска минимальны, они «подстрахованы» налоговыми каникулами и федеральными субсидиями для малого бизнеса. Однако и для их получения необходимо пройти определенные процедуры.

В таких условиях только федеральных субсидий будет недостаточно, необходимо привлечение инвестиций. В регионе действуют не только субъекты малого предпринимательства, но и значительная доля средних и крупных организаций, которые являются основными налогоплательщиками. Для покрытия госдолга этих средств недоста-

\section{Инвестиционный риск регионов ЮФО в 2016 году}

Таблица 1

\begin{tabular}{|c|l|c|c|c|c|c|c|}
\hline $\begin{array}{c}\text { Ранг } \\
\text { риска }\end{array}$ & \multicolumn{1}{|c|}{ Регион } & $\begin{array}{c}\text { Социальный } \\
\text { риск }\end{array}$ & $\begin{array}{c}\text { Экономичес- } \\
\text { кий риск }\end{array}$ & $\begin{array}{c}\text { Финансовый } \\
\text { риск }\end{array}$ & $\begin{array}{c}\text { Криминаль- } \\
\text { ный риск }\end{array}$ & $\begin{array}{c}\text { Экологичес- } \\
\text { кий риск }\end{array}$ & $\begin{array}{c}\text { Управленчес- } \\
\text { кий риск }\end{array}$ \\
\hline 1 & Краснодарский край & 19 & 1 & 19 & 22 & 10 \\
\hline 21 & Ростовская область & 32 & 6 & 56 & 25 & 35 & 29 \\
\hline 52 & Волгоградская область & 41 & 63 & 37 & 60 & 39 & 70 \\
\hline 61 & Астраханская область & 64 & 61 & 57 & 68 & 53 \\
\hline
\end{tabular}

Примечание. Составлено авторами по: [5]. 
точно, нужны новые налогоплательщики. За прошедший год было реализовано 19 инвестиционных проектов и привлечено более 135 млн руб., в том числе строительство высокотехнологичного тепличного комплекса для производства овощей с площадью теплиц 20 га в ООО «Овощевод» г. Волжский. Введены 1-я и 2-я очереди строительства теплиц площадью 10 га.

Строительство теплиц - весьма перспективный бизнес для нашего региона, приоритетный в связи с санкциями Евросоюза. Доля Волгоградской области в 2015 г. в общероссийском производстве тепличных овощей составила $4,6 \%$, уступая лидерам. Тепличный рынок сейчас очень динамичен, основным тормозящим фактором увеличения обеспеченности россиян отечественными тепличными овощами и зеленью является слишком медленное наращивание производственных мощностей промышленных теплиц. Тепличный бизнес очень энергоемок (газ, электричество), поэтому многие хозяйства строят собственный (а порой и несколько) энергоцентр. Стоимость 1 га. промышленной теплицы 4-го или 5-го поколения обычно лежит в пределах 2-3 млн евро (144-215 млн руб. по курсу ЦБ). Рост тарифов энергоснабжения в нашем регионе создает финансовые и экономические риски всем хозяйствующим субъектам, некоторые из них просто уходят из региона. Например, «Волтайр» перевел часть номенклатуры из Волжского в Омский шинный завод только потому, что там ниже цена электричества.

Следует отдельно отметить риски сельхозпроизводителей. Совокупный объем производства АПК Волгоградской области в 2016 г. составил 158 млрд руб., то есть на $26 \%$ больше, чем в 2015 году. Индекс производства продукции сельского хозяйства в IV кв. 2016 г. составил 128,7 \%, в І кв. 2017 г. - 105,6\%. За прошедший год в регионе было собрано 4,6 млн т зерна и порядка 1 млн т овощей это наилучшие показатели за последние 15 лет. А по сбору технических культур (подсолнечника) установлен исторический рекорд - более 1 млн т. Но высокий урожай снизил закупочную цену и повысил риски неплатежей по кредитам. В сельском хозяйстве наблюдается концентрация риска: и низкий урожай, и высокий приводят к рискам.
Следующий по уровню риска - экономический риск. В области очень высокий показатель износа основных фондов - 52,4 \%, это значение соответствует 65-й позиции по России в 2015 году. Наихудшее значение среди субъектов ЮФО остается за Волгоградской областью с 2010 г. [6, с. 694]. В оптовой и розничной торговле степень износа составляет $71 \%$, а это $30 \%$ от общего числа предприятий области. В тройке лидеров по ВРП - сельское хозяйство и обрабатывающие производства: на предприятиях этих видов деятельности износ ОПФ составил 38,4 \% и 47,3 \% соответственно. Отметим, что сельхозпроизводители с помощью субсидий приобрели 1190 машин по цене на четверть меньше рыночной стоимости, такого обновления не было в регионе несколько десятилетий $[2$, с. 10].

В строительстве - износ $62,8 \%$ основных фондов, на долю этого вида деятельности приходится 9,6 \% предприятий. 52,1 \% износа основных фондов на предприятиях по добыче полезных ископаемых.

Снова наихудшие результаты области в ЮФО по удельному весу полностью изношенных ОПФ - 24,6\%. По России в целом мы уступаем только Чеченской Республике $(30,6 \%)$ и Оренбургской области $(31,4 \%)$ на конец 2015 года. Иными словами ситуация также, как и с госдолгом области, катастрофическая [6, с. 694]. 51 \% полностью изношенного ОПФ Волгоградской области приходится на оптовую и розничную торговлю. Высоки технические риски, сбои в поставке продукции, ее порча. Экономический эффект от таких рисков известен. Промышленные предприятия региона, безусловно, подвержены огромному производственному риску: усиление деградации промышленности, низкий технологический уровень большинства производств, прогрессирующая инновационно-технологическая отсталость промышленных предприятий, увеличение разрыва в уровне используемых технологий по сравнению с зарубежными компаниями-конкурентами, устойчивая тенденция сокращения численности работников крупных и средних промышленных предприятий города Волгограда, а также банкротство и предбанкротное состояние ряда ведущих предприятий. Пожалуй, к общим рискам промышленных предприятий 
можно отнести непрерывное повышение тарифов на энергоносители, о чем уже упоминалось. Для химического производства, перспективного направления в регионе (промышленная площадка ОАО «Каустик» для индустриального парка «Никохим», Волгоградский филиал ООО «Омсктехуглерод», ООО «ЕврохимВолгаКалий» в перспективе) это усугубляет высокую энергоемкость технологических процессов.

Доля убыточных организаций на 01.012015 г. составила 34,75\% (рост на $1 \%$ по сравнению с 2014 г.). На 01.012016 г. количество убыточных организаций почти 18,9 тыс. ед. На 01.012017 г. вес убыточных организаций составил 15,8 \%. Прибыль организаций в Волгоградской области (за исключением финансово-кредитных учреждений) за I кв. 2017 г. по отношению к аналогичному периоду предыдущего года упала сразу на $45 \%$.

Экономические риски в среднесрочной перспективе приведут к социальному риску, поскольку большая часть населения работает в сфере оптовой и розничной торговли, оборот которых упал на $1,7 \%$ и 9,2 \% соответственно в 2016 году. Более того, наблюдается рост занятых в этой сфере и снижение в сельском хозяйстве и обрабатывающем производстве (табл. 2).

Уровень безработицы снижается с 7,2 \% в 2015 г. до $6,8 \%$ в 2016 году. На январь 2017 г. - 7 \%. Показатель социального риска достаточно высокий, средний по России. Численность населения с денежными доходами ниже величины прожиточного минимума в области возрастает с 2012 г. и в 2016 г. составила $15,1 \%$. Реальные располагаемые доходы снижаются за период 2014-2016 гг. со $100,1 \%$ до 91,2\%. Косвенно это говорит о снижении покупательной способности населения, снижении спроса на товары/услуги.
Отметим, что в докладе РСПП (Российский союз промышленников и предпринимателей) за 2016 г. проблема снижения спроса - первая в списке проблем для бизнеса (см. рис. 1).

Снижение спроса, платежеспособности потенциальных покупателей продукции повышают вероятность коммерческого риска предпринимательской деятельности. А достаточно высокий процент дорог, не отвечающих нормативным требованиям качества, малая площадь дорог с твердым покрытием резко увеличивают и транспортный риск. Более того, отсутствие объездной (за городом Волгоград) дороги ограничивает транзитный потенциал, и весь большегрузный транспорт идет по улично-дорожной сети южной части города, что негативно сказывается на состоянии полотна и экологической ситуации.

Общероссийская тенденция - недостаток квалифицированных кадров (рис. 1, 31 \% опрошенных предпринимателей отметили этот фактор риска) - свойственна и для промышленных предприятий Волгоградской области. Потребность в рабочих и инженерных кадрах до 2021 г. составляет свыше 11 тыс. рабочих мест, в том числе машиностроительный комплекс - 3 тыс., химический и металлургический - по 2 тыс. До 2023 г. - потребность в 17 тыс. рабочих мест в связи с ростом инвестиционных проектов. На фоне снижения индекса производительности труда эти обстоятельства говорят о вероятности возникновения производственных рисков, прежде всего на промышленных предприятиях.

Риски в бизнес-среде оцениваются еще таким показателем, как просроченная кредиторская задолженность предприятий и организаций (задолженность хозяйствующего субъекта перед другими лицами, которую он обязан погасить). Этот показатель можно найти в методике Эксперт РА.

Таблица 2

Доля занятого населения Волгоградской области по видам деятельности, \%

\begin{tabular}{|l|c|c|c|}
\hline \multicolumn{1}{|c|}{ Вид деятельности } & 2013 г. & 2014 г. & 2015 г. \\
\hline Оптовая и розничная торговля & 19,3 & 19,5 & 19,6 \\
\hline Сельское хозяйство & 17,1 & 16,3 & 16,0 \\
\hline Обрабатывающее производство & 15,1 & 14,9 & 14,5 \\
\hline
\end{tabular}

Примечание. Составлено авторами по: [6, с. 694]. 
На рисунке 2 представлены данные по организациям Волгоградской области, других субъектов ЮФО.
Финансовые риски оценены агентством «Эксперт РА» на уровень ниже, чем остальные по Волгоградской области. Тем не менее

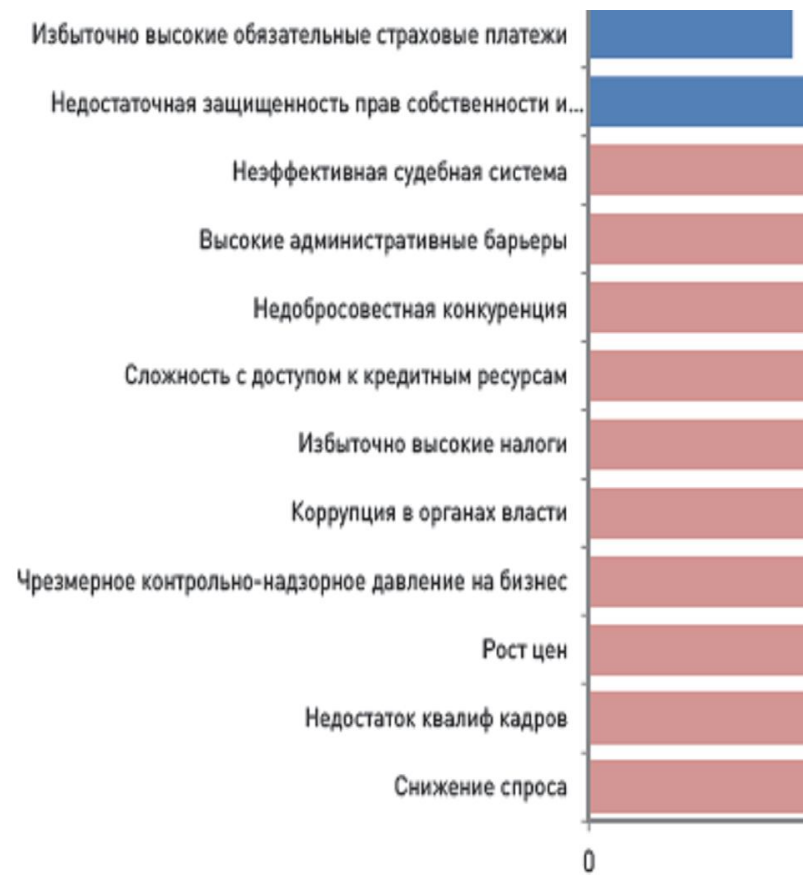

Рис. 1. Наиболее острые проблемы для бизнеса в России, 2016 год

Примечание. Составлено авторами по: [3, с. 24].

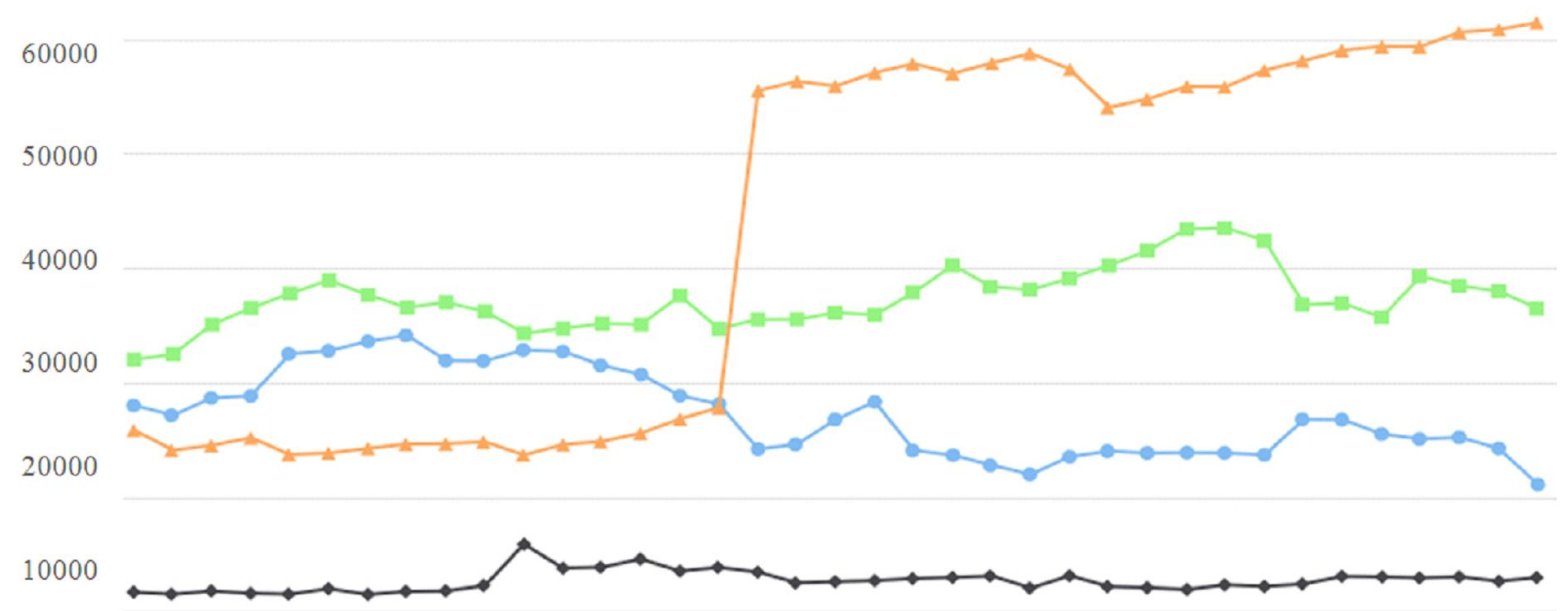

0

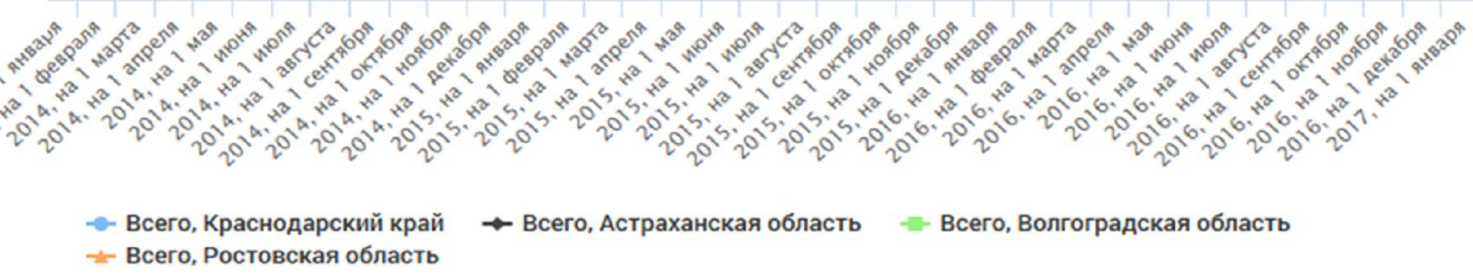

Рис. 2. Просроченная кредиторская задолженность организаций 2014-2017 гг., тыс.руб.

Примечание. Составлено авторами по: [5]. 
для субъектов предпринимательской деятельности в регионе он существенен. Если предприятие планирует крупный инвестиционный проект, то без государственной поддержки это будет достаточно сложно осуществить.

По общему тренду кредиторской задолженности организаций Волгоградской области динамика возрастающая.

Таким образом, в Волгоградской области существенны управленческие риски (неисполнение бюджета, высокий госдолг и в перспективе его наращивание), высоки промышленные риски в силу сильного износа основных фондов и высокого процента полностью изношенного производственного фонда. Коммерческие риски определяются следующими факторами: падением платежеспособности населения, ростом доли граждан с доходами ниже прожиточного минимума и снижением реальных располагаемых доходов - это основные причины снижения покупательной способности, спроса. В регионе, где основное количество предприятий сосредоточено в сфере оптовой и розничной торговли, создающей 14,5 \% добавленной стоимости, это особенно актуально. Кроме того, экономический риск отягощают снижение производительности труда и нехватка квалифицированных рабочих в промышленности. Локальные риски нельзя рассматривать независимо друг от друга, они взаимообусловлены и взаимосвязаны, также как и локальные риски хозяйствующих субъектов. Риски возникают при их взаимодействии, эти риски крайне тяжело выявить. На этапе идентификации рисков на конкретном предприятии строится «дерево» рисков (карта взаимосвязи и взаимовлияния внутренних и внешних рисков в компании). Крупные предприятия подвержены большей вероятности рисков в силу перечисленных обстоятельств, малый бизнес - в меньшей степени на начальном этапе функционирования (доступность кредитов - сложность процедуры получения банковских кредитов, высокие процентные ставки, залог, неразвитость альтернативных механизмов финансово-кредитной поддержки формируют финансовый риск). Существует недостаточная осведомленность о возможностях господдержки.

В регионе традиционно в лучшем положении предприятия ТЭК (они в десятке пер- вых налогоплательщиков и инвесторов), крупные инвестиционные проекты начаты в химической промышленности. Наибольшие риски у предприятий оптовой и розничной торговли, строительства. Большие риски традиционно сопровождают сельскохозпроизводителей, но они вместе с предприятиями химической отрасли пользуются господдержкой.

Анализ условий осуществления предпринимательской деятельности позволил выявить риски и основные направления их регулирования:

1. Административно-правовое направление представлено страхованием от политических рисков и внедрением с 2017 г. риск-ориентированного подхода в контрольно-надзорную деятельность государства.

Возникающие риски определяются внешними факторами, на которые мало кто может влиять. Тем не менее распространена практика страхования политических рисков. Так, АО «ЭКСАР» является первым экспортным агентством в истории России, которое осуществляет страхование экспортных кредитов и российских инвестиций за рубежом от политических рисков. Например, компания «Омск Карбон Групп», крупнейший производитель технического углерода, в состав которой входит ООО «Омсктехуглерод» (г. Волгоград, входит в топ-20 по налоговым отчислениям в бюджет региона в 2016 г.), заключила договор страхования инвестиций (строительство завода в Республике Беларусь) от рисков утраты в результате событий политического характера.

Высокие управленческие риски в региональных органах власти отчасти могут быть нивелированы внедрением риск-ориентированного подхода, который позволит снизить общую административную нагрузку на субъекты предпринимательской деятельности, повысить эффективность контрольно-надзорной деятельности при оптимальном использовании материальных, финансовых и кадровых ресурсов органов государственного контроля.

Этот подход лежит в основе принятия решений в сфере государственного регулирования, включая принятие новых требований, распределение бюджетного финансирования, классификацию видов контроля. В числе ожидаемых результатов - актуализация требова- 
ний (исключение избыточных, устаревших, дублирующих обязательных требований) для розничной торговли, производства продуктов, операций с недвижимостью и др.; создание «прозрачных условий осуществления предпринимательской деятельности». Внедрение риск-ориентированного подхода - это пример компенсации риска путем организации системы управления рисками на региональном мезоуровне.

2. Экономическое направление регулирования предпринимательских рисков:

- диверсификация деятельности отдельного предприятия и диверсификация экономики региона (считается приоритетным направлением для Волгоградской области, поскольку экономика и социальная составляющая региона находятся в кризисном состоянии);

- страхование производственных рисков и рисков неплатежей, комплексное страхование компаний-экспортеров, в том числе деривативы применяются как инструменты страхования кредитных и валютных рисков;

- способы и меры снижения налоговых рисков (наблюдается практика привлечения к субсидиарной и уголовной ответственности предпринимателя за задолженность предприятия по налогам и перед партнерами [4]);

- гарантии государства (налоговые льготы, «Программа 6,5 \%» и прочие льготные займы и меры господдержки) как способ снижения рисков.

Анализ существующих предпринимательских рисков в регионе, условий осуществления хозяйственной деятельности субъектов показал, что практика применения различных способов снижения рисков невысока. Дополнительные затраты и низкая осведомленность, культура управления являются основными причинами. На эту же причину указывают региональные власти, говоря о нежелании промышленных предприятий участвовать в госпрограммах. Эксперты, в свою очередь, отмечают высокие барьеры такого участия [7, c. 639].

Предприятия области, которые уже получили льготные займы через ФРП (ОАО «Волгоградский керамический завод», Волгоградский алюминиевый завода («РУСАЛ»), ЗАО «НПО «Ахтуба» и др.), страхуют производственные риски и на текущий момент опосредованно участвуют в создании комплексной региональной системы подготовки рабочих и инженерных кадров.

Так, страхование ответственности товаропроизводителя выступает инструментом минимизации рисков промышленных предприятий Волгоградской области. Производство и реализация товаров могут повлечь причинение вреда жизни, здоровью или имуществу третьих лиц (потребителей) и независимо от того, состояли ли они в договорных отношениях с производителем, ущерб (вред) подлежит возмещению. Это может нанести удар по финансовой устойчивости не только промышленного предприятия (любо компании), отвлечь денежные средства от основной деятельности производителя (продавца), нанести ущерб его репутации. Страхование помогает избежать указанных негативных последствий.

Со стороны бизнеса наблюдается спрос на банковские гарантии и аккредитивы [1, c. 3-14]. Эти инструменты страхуют риски неплатежей, поскольку внутри компаний рискменеджмент не так развит, как в банке. Кстати, многие страховые компании предлагают продукт «страхование предпринимательских рисков». Наиболее популярными программами кредитования бизнеса у банков в настоящее время стали кредиты на пополнение оборотных средств.

Таким образом, можно отметить, что среди основных направлений регулирования предпринимательских рисков, выделенных с точки зрения видов рисков, приоритетным направлением для Волгоградской области в силу не лучших социально-экономических условий развития предпринимательской деятельности считается диверсификации экономики региона.

\section{СПИСОК ЛИТЕРАТУРЫ}

1. Артемов, С. С. Три фактора роста / С. С. Артемов // Коммерсантъ. - 2016. - Вып. 231. - С. 13-14.

2. Дмитриева, Т. Т. Кризисный тонус / Т. Т. Дмитриева//Коммерсанть. -2017.--№53.-С. 10.

3. Доклад «О состоянии деловогоклимата в России в 2016 году». - Электрон. текстовые дан. - Москва, март 2017 года. - Режим доступа: http://media.rspp.ru/ document/1/f/9/f9c2ca5f8cd104f8d5d40f2a7b50fced.pdf.Загл. с экрана. 
4. Портнов, Г. В режиме диалога / Г. Портнов, Е. Борисенкова // Коммерсантъ. - 30.03.2017. Электрон. дан. - Режим доступа: https://www. kommersant.ru/doc/3256669\#comments. - Загл. с экрана.

5. Рейтинги, Рэнкинги. Инвестиционные рейтинги регионов России, 2016 г. // RAEX = Эксперт PA : Рейтинговое агентство : [офиц. сайт]. - Режим доступа: http://raexpert.ru/ratings/regions. - Загл. с экрана.

6. Регионы России. Социально-экономические показатели, 2016 : стат. сб. - М. : Росстат, 2016. $1326 \mathrm{c}$.

7. Buyanova, M. E. Risks of entrepreneurial activity in a region: assessment and regulation / M. E. Buyanova, N. A. Mikhaylova // Advances in Economics, Business and Management Research. Vol. 39. Competitive, Sustainable and Secure Development of the Regional Economy: «Response to Global Challenges». - Los Angeles : Atlantis Press, 2018. - P. 635-640.

\section{REFERENCES}

1. Artemov S.S. Tri faktora rosta [Three Growth Factors]. Kommersant, 2016, no. 231, pp. 13-14.
2. Dmitrieva T.T. Krizisnyy tonus [Crisis Tone]. Kommersant, 2017, no. 53, p. 10.

3. Doklad «O sostoyanii delovogo klimata $v$ Rossii v 2016 godu» [Report 'On the Condition of Business Climate in Russia in 2016']. Moscow, 2017. URL: http://media.rspp.ru/document/1/f/9/f9c2ca5f 8cd104f8d5d40f2a7b50fced.pdf

4. Portnov G. V rezhime dialoga [In the Dialogue Mode]. Kommersant, 2017 (March 30). URL: https:// www.kommersant.ru/doc/3256669\#comments.

5. Reytingi, Renkingi. Investitsionnye reytingi regionov Rossii, 2016 g. [Ratings. Rankings. Investment Ratings of Russian Regions, 2016]. RAEX $=$ Ekspert RA : Reytingovoe agentstvo:ofits. sayt [Official Website of the Rating Agency Expert RA]. URL: http://raexpert.ru/ratings/regions.

6. Regiony Rossii. Sotsialno-ekonomicheskie pokazateli, 2016: stat. sb. [Regions of Russia. SocioEconomic Indicators, 2016]. Moscow, Rosstat Publ., 2016. 1326 p.

7. Buyanova M.E., Mikhaylova N.A. Risks of Entrepreneurial Activity in a Region: Assessment and Regulation. Advances in Economics, Business and Management Research. Volume 39. Competitive, Sustainable and Secure Development of the Regional Economy: Response to Global Challenges. Los Angeles, Atlantis Press, 2018, pp. 635-640.

\section{Information about the Authors}

Marina E. Buyanova, Doctor of Sciences (Economics), Professor, Head of Department of Economic Theory, Politics and Regional Economics, Volgograd State University, Prosp. Universitetsky, 100, 400062 Volgograd, Russian Federation, buynovam@rambler.ru.

Nataliya A. Mikhaylova, Candidate of Sciences (Economics), Associate Professor, Department of Management and Entrepreneurship, Moscow State University of Humanities and Economics, Losinoostrovskaya St., 49, 107150 Moscow, Russian Federation, korish.m@volsu.ru.

\section{Информация об авторах}

Марина Эдуардовна Буянова, доктор экономических наук, профессор, заведующая кафедрой экономической теории, политики и региональной экономики, Волгоградский государственный университет, просп. Университетский, 100, 400062 г. Волгоград, Российская Федерация, buyanovam@rambler.ru.

Наталия Александровна Михайлова, кандидат экономических наук, доцент, доцент кафедры управления и предпринимательства, Московский государственный гуманитарно-экономический университет, ул. Лосиноостровская, 49, 107150 г. Москва, Российская Федерация, korish.m@volsu.ru. 